\title{
Cycling in the city, reduction of greenhouse gas emissions and economic impact on tourism: case study of Puebla, Mexico
}

\author{
Y. D. Bussière ${ }^{1}$, I. Espinosa Torres ${ }^{2}$, J.-L. Collomb $^{3}$ \& E. Ravalet ${ }^{4}$ \\ ${ }^{I}$ Faculty of Economics, Benemerita Universidad de Puebla, Mexico \\ ${ }^{2}$ Institute of Social Sciences and Humanities, \\ Benemerita Universidad de Puebla, Mexico \\ ${ }^{3}$ SETEC, Paris, France \\ ${ }^{4}$ CERTU, Lyon, France
}

\begin{abstract}
Cycling in the city, a practice which had been lost progressively since the 1960s with the rapid expansion of the use of the automobile, has recently become common practice in many cities of the North where the bicycle had almost disappeared. Urban speedways and viaducts built in the 1960s are being reconsidered and even destroyed to give place to boulevards and a friendlier urban environment for pedestrians. Many examples are available: Lyon with the introduction of Velo'V in 2005, Paris with the introduction of Veli'b in 2007 and Montreal with the introduction of BIXI in 2009 are recent experiences which may be cited as best practices. Could similar policies be applicable to Latin American cities where the use of the bicycle has been progressively abandoned but seems to have now a regaining image? What could be its potential impact on diminishing greenhouse gas emissions? What could be its potential impact on tourism? After a rapid review of various experiences in Europe, Canada and Latin America, we will focus on the example of Puebla, a city of 1.5 million inhabitants in the Centre-East of Mexico, for which we collected data in an opinion survey (2007-8) on non motorized modes. This case study leads to conclusions on the feasibility of such policies in a South American context and its potential impact in terms of sustainability as well as in economic benefits via the tourist industry. An approximation of the emissions in urban transportation that can be saved by the practice of the bicycle for utilitarian an leisure purposes and multimodality Bike-Public Transport, facilitated by the rent-a-bike systems,
\end{abstract}


gives us a tangible reduction of the emissions of around 3\% of urban transport of persons and $0.5 \%$ of total emissions in conservative scenarios. Furthermore these environment friendly policies, in cities like Puebla, a UNESCO World Monument city with strong tourist activity, could induce enormous economic benefits (in the range of 500 million US\$ a year) by prolonging the average stay of tourists of a few days.

Keywords: cycling, rent-a-bike, GHG, tourism, economic impact, Puebla, Mexico.

\section{Introduction}

Sustainable development in cities to reduce global warming is one of the challenges that human society will have to face in the next few decades. In Northern countries the level of population is more or less stabilized, the technology is progressively getting cleaner, but the behaviors are still aligned on increasing consumption in a context of urban sprawl which leads to more GHG emissions. In countries of the South the context is very diverse depending on the level of development. If we look at future prospects, the threat will come from emerging countries where the rate of growth of population is still high, the economic development rapid, and the behaviors aligned on the American model, with a high consumption of energy. The countries of Latin America will see a strong demographic growth, probably also a strong economic development and possibly behaviors aligned on the North American model.

Moreover, the sources of GHG emissions are diverse and linked to the life style requiring energy, the growth of motorization, the deforestation, agriculture, etc. [21]. To slow down the actual tendency of increasing GHG emissions, we rapidly arrive to the conclusion that we will need a sum of many measures, even very small ones, mainly in developed or emerging countries.

The paper is divided in 3 parts: a rapid review of best practices of cycling in the city; results of a survey in Puebla on the use of non-motorized modes and its impact on tourism; an evaluation of the impact of the use of the bicycle on the reduction of GHG.

\section{Cycling in the city: various examples}

The practice of the bicycle in European cities is very diverse. It reaches high levels in Northern cities (around $20 \%$ to $30 \%$ of all trips) [13] and very low levels in cities of Southern Europe, like France, Spain or Italy with a few exceptions in cities where pro-bicycle policies have been implemented such as Strasbourg (8\%). But things are changing and such policies like those taken in Lyon and Paris with the implementation of cycle paths and bicycle renting have an important impact of the practice of the bicycle. Policies favorable to the use of the bicycle in the city have proven to be efficient. 


\subsection{The example of Lyon}

The practice of the bicycle had almost disappeared in Lyon with only $0.73 \%$ of total trips in 1995. It had reached $1.64 \%$ in 2006 , a progression in one year most probably due to the introduction in May 2005 of the renting system in self service, Vélo' $\mathrm{V}$, implemented in the central part of the urban area of Lyon to promote the use of the bicycle not only of leisure but also for utilitarian purposes. The Rent a Bike facilitates the use of the bicycle by making it easier, more flexible [20]. It permits to the users to take a bike in any station on the territory covered by the service and to bring it back in any other station of the territory. A membership card or a credit card gives access to this type of service. The cost is very accessible for the user. JCDecaux and Clear Channel are responsible of the vast majority of ongoing projects. The great advantage of the system Rent a Bike in comparison to the use of a personal bicycle is that it facilitates multimodality since it is not necessary to transport the bicycle in the car, the bus or the metro to use it for the total trip, which favors long trips combining bike-public transportation. Moreover, in many occidental cities, to use the bicycle in the city has become fashionable, and the Rent a Bike enjoys a good image a la mode. The social perception of the mode of transportation is important. Lyon had in 2008 around 400 stations distributed on the territory every 300 meters or so, on a good proportion of the areas of Lyon and Villeurbanne. The stock of bicycles is of around 4000 , some of which are under repair. The repair costs (wear, voluntary degradation and thefts) is around $1000 €$ per year and per bike [19]. The membership cost (in 2009) is cheap ( $1 €$ per week or ou $5 €$ per year). For each renting, there is a free period of $1 / 2$ hour to 1 hour (depending on the type of membership) followed by a paying period (from 0,5 to $1 €$ per additional hour) [14]. Based on Household OriginDestination surveys of Lyon in 1995-1996 and 2006 [8, 18] we can measure the rapid change in mobility behavior in favor of the mode Vélo' $V$ and general use of the bicycle: it has progressed by $124 \%$ in the urban area of Lyon.

\subsubsection{Who are the cyclists in Lyon?}

The population of cyclists, defined as the residents who have used a bicycle for at least one of their trips captured during the day of the survey, is composed of $75 \%$ men and of $25 \%$ women, in 1995 but also in 2006 . The proportion of cyclists is higher for adults in the age group 30-35 years. In volume, we notice the importance of workers, whose proportion passes from $41 \%$ of the total population of cyclists in 1995 to $59 \%$ in 2006 . However, in relative terms, it is in the category of students that the practice of the bicycle remains most important (4.7\% of the students are cyclists vs. 3.5\% of the workers). Between 1995 and 2006 , the social composition of the cyclists progressed in favor of the population of higher incomes. This reinforces the idea that the image of the cyclist is important and that it should be positive to favor the use of the bicycle and an eventual modal change from the auto to the bike. Velo'V was accompanied by a revolution of the image of the bicycle in Lyon. This is an essential point if we wish a positive evolution of the practice of the bicycle in cities of the South in 
general, and more specifically in cities of Latin America where the image of the "functional" use of the bicycle is associated with poverty.

\subsection{The case of Paris and of other European cities}

The City of Paris has implemented its system of Rent a Bike, similar to the Lyon system, the Velib', in July 2007. In 2008 the system had already 1450 stations for 20600 bicycles and the use of the bicycle has passed from $2 \%$ to $3 \%$ of total trips. The objective is to attain 4 to $5 \%$ in 2010 and 6 to $8 \%$ in 2020 . As in the case of Lyon, the administration of the system is done by the firm JCDecaux which finances the operation with publicity on the urban furniture. Other formulas are also possible, as for example, in Barcelona where the administration is done by Clear Channel and the financing is assured by the surplus in parking revenue. These systems have spread out rapidly and we can find them now in various European cities: In France: Toulouse, Dijon, Marseilles,...; in Austria: Vienna; in Spain: Barcelona and Sevilla, to give only a few examples.

\subsection{The case of Montreal}

The Rent a Bike in Montreal (BIXI) started in Abril 2009 on the Lyon model with a more sophisticated wireless technology which gives more flexibility to the system, as removing the stations for the winter season. In September 2009 there were 3000 bicycles distributed in 300 stations in the center of Montreal. This system was so popular that it was rapidly exported to various cities, namely, Ottawa, London (U.K.), Boston, Washington, Melbourne. By mid-August 2009 it had 8419 members, 77070 occasional users and $3612799 \mathrm{~km}$ travelled [1].

\subsection{The case of Bogotá}

The City of Bogota has implemented in December 2000 an integral plan of transportation favoring the use of the public transport and non-motorized modes, the STIM (Sistema Integrado de Transporte Masivo) known as the Transmilenio. This plan included, among other things, the implementation $300 \mathrm{~km}$ of cycloroutes. To these measures other elements were introduced to favor the use of the bicycle such as the day without autos in the center, every year. These policies induced a strong progression of non-motorized modes, which passed from $9 \%$ to $13 \%$ of total trips between 1998 and 2002. The use of the bicycle has passed from $0.58 \%$ in 1996 to $4.4 \%$ in 2005 , with $2 \%$ in cyclo-routes [17]. Public transport passed from $72 \%$ to $73 \%$ and Auto from $16 \%$ to $11 \%$ [3]. Policies favorable to non-motorized modes can therefore be efficient even in cities where we would a priori think the contrary. Other examples in Europe, like Barcelona where the use of the bicycle was very low, give similar results.

\subsection{The case of Monterrey}

Monterrey is a northern city of Mexico of 3.7 million inhabitants, located at 230 $\mathrm{km}$ south of the US border. Due to this proximity to US, we find a higher level of motorization than in southern cities with the following modal split, according to 
the Origin-Destination Survey of 2005 auto-driver: 23.8\%; auto-passenger: $12.8 \%$; public transportation: $43 \%$, transport of personnel by firms: $2.1 \%$; school transportation: $1.4 \%$; taxi: $6.3 \%$, bicycle: $0.8 \%$, walking and others: $10 \%$. Based on two surveys realized during the autumn of 2008 for the implementation of a Bus Rapid Transit [12] on users of public transportation: one survey on 300 users of public transportation, the other on 1514 car drivers. From the first survey on users of Public Transportation, $75 \%$ of the respondents are favorable to a multimodality between public transport and the bicycle with a possibility of parking and $58 \%$ declare that they would use it. Women are more favorable than men for this type of multimodality (78\% vs. $74 \%$ ) but slightly less favorable to use it (65\% vs. $44 \%)$. The second survey, gives the following results. Firstly, $95 \%$ of the car drivers say that they would use the new system of public transportation (a proposed line of BRT) if it was modern, rapid, with air conditioning and if it would reduce the time of travel, at the condition however that the waiting time does not increase, or the proportion decreases to $65 \%$. $91 \%$ of the car drivers are favorable to the implementation of cyclo-routes and incitative parkings with little gender differences. To the question if they would use the system, the level of approbation is high but men are more favorable $(85 \%)$ than women $(76 \%)$. We find here a gender difference similar to Lyon but less pronounced. These results show clearly that the population, the users of public transportation or car drivers, are open to policies favoring the use of the bicycle and multimodality bicycle-other modes.

\section{The case of Puebla}

Puebla is a mid-sized city of Mexico of 1.5 million inhabitants located 2 hours driving south-east of Mexico City. According to the last Origin-Destination survey (1994) [10], the modal split was the following: auto: 19\%, public transportation: $48 \%$, walking: $27 \%$; bicycle: $2 \%$; others: $4 \%$. The demographic context is one of rapid growth (average annual growth between $1.5 \%$ and $2 \%$ ) and individual motorization augments 3 to 4 times that of the population [6]. The modal split of public transport should be around $40 \%$ today. What is the situation of the non-motorized modes - bicycle and walking? A recent study based on surveys done face to face in various pubic places of the city with a sample of 1162 persons gives us an idea of the perception of these modes and their potential [4,5,21]. The surveys were realized between November 2007 and January 2008 with the following distribution, each with a distinct questionnaire: residents of Puebla: 586; tourists: 301; enterprises: 113; informal merchants or ambulantes: 99; parking lots: 63.

\subsection{Results on residents of Puebla}

Although the best source to obtain the modal split is the household OriginDestination Survey, without a recent survey, our person to person survey on a sample of persons encountered in public spaces gives us a good idea of the actual modal split, which would be the following: auto-driver $32.4 \%$; auto-passenger $12.6 \%$; public transportation: $40.3 \%$; taxi: $0.3 \%$; bicycle: $1.9 \%$; walking: $9.7 \%$; 
others: $0.7 \%$. The residents of the Historic Center walk much more with $24 \%$ of total trips at the expense of auto-driver, the modal split of the other modes being comparable. The questionnaires administered seeked to measure the opinion on three aspects: the implementation of pedestrian zones in the Historical Centre, cycle-paths and a Rent a Bike system inspired on the European example. The answers of the different questionnaires give us an interesting insight on the potential of non-motorized modes if adequate policies were adopted. Firstly, $60 \%$ of the residents of Puebla express a dissatisfaction of the actual situation of transportation in the Historical Center. Also, 76\% declare using the bicycle. This mode, even though is represents a small proportion of the total trips, stays very present and could have a potential. The residents of Puebla approve by $76 \%$ to transform the Zócalo (Central place) and the neighboring streets in a walking zone; by $74 \%$ to introduce cycle-paths in the Historical Center; by $59 \%$ to introduce cycle-routes outside the Historical Center; by $68 \%$ to introduce a system of renting bicycles with a price competitive with public transportation. At the question: Would you use the bicycle routes? 74\% answered "yes". What is the opinion of the businesses located in the Center, close to the proposed pedestrian zones? They are also favorable by $59 \%$ to make the Center pedestrian and $46 \%$ think that these measures will benefit their business. The informal business or "ambulantes" approve by $60 \%$ the introduction of measures favorable to non-motorized modes and $81 \%$ say that they would respect the public spaces reserved to pedestrians and bicycles. The parking lots of the Center are favorable by $48 \%$ for policies favorable to make the Center pedestrian and $59 \%$ are favorable for bicycle-routes. According to this survey it seems that the local population, the tourists and the businesses are very receptive to the introduction of policies favorable to non-motorized modes and that the direct economic impact of such policies would be largely positive due to the importance of the tourist activity in Puebla, without taking in account other positive impacts such as decongestion, a better air quality and, finally, a better quality of life.

\subsection{Results of tourists in Puebla}

The tourist activity in Puebla is important. The tourists are very favorable for the implementation of policies pro non-motorized: $89 \%$ say that they would prolong their stay if the Zócalo (Central Place) and neighboring streets was transformed in a pedestrian zone and if were introduced bicycle paths and a system of Rent a Bike: $22 \%$ would prolong their stay one day, $29 \%$ two days; $28 \%$ three days; $13 \%$ four days or more. The average stay declared sums up to 1.46 days. A gross evaluation of the economic impact can be done by multiplying: the annual number of tourists $\mathrm{x}$ the average stay $\mathrm{x}$ the daily expenditures $\mathrm{x}$ a Keynesian multiplier (3 $720000 \times 1.46 \times 672$ Mexican pesos x 1.50). We obtain an impact of more than 5.5 billion pesos annually (around $\$ 570$ million dollars US at the moment of the study). A very high social benefit if compared to the cost of the infraestructure which would be roughly 150000 pesos per km (12 500 \$US). If we imagine an initial red of $200 \mathrm{~km}$ the initial cost of $\$ 2.5$ million (\$US) would be recovered the first year. As for the operating costs of a Rent a Bike system at 
a price equivalent to the public transportation, we estimated that it would need public subsidies or complementary financing from publicity, parking, or other sources of roughly $\$ 4$ million (\$US) only for the first two or three years. A detailed Benefit-Cost Analysis would undoubtedly lead to very positive results.

\section{Impact of bicycle use in Puebla on reduction of GHG}

We calculated the impact of the use of the bicycle in Puebla on the reduction of $\mathrm{CO}_{2}$ emissions [4]. The results of any model, even the most sophisticated, will depend on the initial calibration and in this area we often lack of exact data. Our objective here is to give an idea of the magnitude of the possible reduction of $\mathrm{CO}_{2}$ emissions due to non-motorized modes.

After a brief presentation of the context of $\mathrm{CO}_{2}$ emissions in Mexico, we will present the main results of the reduction of $\mathrm{CO}_{2}$ emissions which could induce the use of the bicycle in Puebla in 2005. Furthermore a scenario of growth of the proportion of the use of the bicycle will be applied over a period of 15 years and we will present an estimation of potential reduction for the year 2020 in a context where policies favorable to the bicycle were adopted. Finally, from the results of the survey in Monterrey on intermodality Bike-Public transport, we will present a simulation of the possible impact of such a practice based on the data of the City of Puebla.

Mexico had global emissions of $553 \mathrm{Mt} \mathrm{CO}_{2}$ eq of GHG in $2002[9,11]$ and the country has since exceeded the level of $600 \mathrm{Mt} \mathrm{CO}_{2}$ eq. This positions Mexico in tenth position of countries emitting $\mathrm{CO}_{2}$ gases in volume [2]. The sector of transportation represented approximatively $20 \%$ of the emissions with $114 \mathrm{Mt} \mathrm{CO}_{2}$ eq in 2002. The main data used in our study is based on the automobile fleet of Puebla; this data is available at the Department of Transportation and Communications of the State of Puebla [16]. The methodology used is based on a Canadian study [7] realized for Vélo Québec. The method consists, at first to calculate the emissions of all modes of transportation in Puebla, then to quantify the practice of the bicycle and the impact that would have generated the trips made in bicycle if they had been made by bus, lighter public transportation (combis), and automobile with the hypothesis that for each mode, supply adjusts to the level of demand. The base year chosen is 2005, corresponding to the year for which we have a complete overview of the motorized fleet of Puebla. For each year until 2020 we applied growth rates of different categories of vehicles according to socio-demographic trends. Once the motorized fleet projected, we calculated the emissions of $\mathrm{CO}_{2}$ for each category of vehicles, a total of 11 . This was done taking into account the level of emissions in 2005 for Mexico for each category according to new vehicles.

To obtain a global level of emissions (new and old vehicles) we calculated for each year a level of emissions for new vehicles based on the precedent year with a correcting factor to take in account the technological progress. We supposed a rate of renewal of the automobile fleet of $8 \%$ per year and an improvement in 
technology (or annual diminution of emissions of new vehicles) of $2 \%$ between 2005 and 2010, and of 4\% between 2010 and 2020. The progressive improvement of emissions of new vehicles seems to have a slow impact on the emissions of the total fleet: according to our model, the emissions of the total fleet were $238.1 \mathrm{grCO}_{2} / \mathrm{km}$ and that of the new vehicles was of $198.4 \mathrm{gr} \mathrm{CO}_{2} / \mathrm{km}$ in 2005 , which leads us, respectively to $173.3 \mathrm{grCO}_{2} / \mathrm{km}$ and $116.8 \mathrm{grCO}_{2} / \mathrm{km}$ in 2020.

In the calculation of the practice of the bicycle we did a distinction of "utilitarian" activities and "leisure" activities and distinguished between weekday activities and weekends and holidays [7]. This distinction permits to calculate a transfer to the cyclist activity from 3 modes (Auto, Public TransportBus, Public-Transport-light) with different coefficients (we used: transfers of the bike utilitarian practice: $30 \%$ from Auto and Public Transport; transfers of the bike leisure practice: $50 \%$ from the Auto and $25 \%$ from Public Transport). The initial modal split of the bicycle was $1.5 \%$ of total trip in 2005 . It has been set in 2020 at $4 \%$ in a first scenario and at $8 \%$ in a second scenario.

The results of scenario 1 are summarized in Table 1 with an estimation of the emissions of $\mathrm{CO}_{2}$ in Puebla due to the cyclist practice in 2005 and 2020 with the modal split of the bicycle augmenting between 2005 and 2010 from $1.5 \%$ to $4.0 \%$ of total trips. This practice permits the economy of 27901 tons de $\mathrm{CO}_{2}$ en 2005 and 52545 tons of $\mathrm{CO}_{2}$ in 2020, that is, 24644 supplementary tons with the modal split of $4 \%$. Compared to the emissions of $\mathrm{CO}_{2}$ emitted by urban traffic in Puebla these figures represent respectively $2.0 \%$ and $3.4 \%$ of the total, excluding the trucking activity, that is, around $0.4 \%$ to $0.68 \%$ of total emissions of $\mathrm{CO}_{2}$. Despite of a proportion of cyclists which has more than doubled in percentage, the proportion of the total reduction of emissions due to the practice of the bicycle has progressed by only $70 \%$ between 2005 and 2020 . This is due essentially to the increasing motorization taken in account in the model.

Other scenarios permit to measure the amplitude of possible impacts of the practice of the bicycle on the reduction of $\mathrm{CO}_{2}$ gases. Thus if the modal split of the bicycle reaches $8 \%$ instead of $4 \%$ in 2020 , a rate that many European cities have already attained or surpassed, the reduction of $\mathrm{CO}_{2}$ induced in proportion of the emissions of urban transport passes from $2.7 \%$ to $5.3 \%$, an equivalent of $1.1 \%$ of total sources of total emissions, which is far from being negligeable.

Also, given the results very favorable to multimodality Bike-Public Transport of the opinion survey of Monterrey, we thought useful to try to approximate the impact of policies promoting this practice on the augmentation of the use of Public Transportation, based on the data of Puebla, with two additional senarios (1a and 2a). With the same model we calibrated the impact of a change in modal split in favor of Public Transportation with the hypothesis that $15 \%$ of the trips made by cyclists would lead to a transfer towards Public Transportation from Auto with average trips of $15 \mathrm{~km}$ in Public Transportation. In a scenario where the modal split is $4 \%$ for the bicycle, we obtain a transfer of $0.6 \%$ of total auto demand towards Public Transportation (scenario 1a) and in the case of a scenario where the modal split of the bicycle is $8 \%$ we obtain a transfer of $1.2 \%$ (scenario 2a). 
Table 1: Reduction of $\mathrm{CO}_{2}$ emissions of public transportation due the practice of the bicycle in Puebla 2005 and 2020 (scenario 1 at $4 \%$ in 2020).

\begin{tabular}{|c|c|c|c|}
\hline & Units & 2005 & 2020 \\
\hline Modal split of the bicycle & $\%$ & 1.5 & 4.0 \\
\hline Cyclist activity & cyclists. km & 158571747 & 514858060 \\
\hline Cyclist activity - utilitarian & cyclists.km & 63670793 & 206729267 \\
\hline Cyclist activity - leisure & cyclists. km & 94900954 & 308128793 \\
\hline Rate of emissions $\mathrm{CO}_{2}$ for the automobile - gasoline & $\mathrm{grCO}_{2} / \mathrm{km}$ & 238 & 173 \\
\hline Rate of emissions $\mathrm{CO}_{2}$ for bus - by passenger & $\mathrm{grCO} / \mathrm{km}$ & 102 & 60 \\
\hline $\begin{array}{l}\text { Rate of emissions } \mathrm{CO}_{2} \text { for light public transport - by } \\
\text { passenger }\end{array}$ & $\mathrm{grCO} / \mathrm{km}$ & 75 & 55 \\
\hline $\begin{array}{l}\text { Emissions of } \mathrm{CO}_{2} \text { generated if the cyclists would } \\
\text { have partially used the automobile* }\end{array}$ & Tons $\mathrm{CO}_{2}$ & 21908 & 37455 \\
\hline $\begin{array}{l}\text { Emissions of } \mathrm{CO}_{2} \text { generated if the cyclists would } \\
\text { have partially used the bus* }\end{array}$ & Tons $\mathrm{CO}_{2}$ & 4103 & 8366 \\
\hline $\begin{array}{l}\text { Emissions of } \mathrm{CO}_{2} \text { generated if the cyclists would } \\
\text { have partially used light Public Transportation* }\end{array}$ & Tons $\mathrm{CO}_{2}$ & 1890 & 6725 \\
\hline $\begin{array}{l}\text { Total emissions due to a transfer of the cyclist activity } \\
\text { on the three modes }\end{array}$ & Tons $\mathrm{CO}_{2}$ & 27901 & 52545 \\
\hline Total emissions of transportation in Puebla & Tons $\mathrm{CO}_{2}$ & 1773620 & 1979941 \\
\hline $\begin{array}{l}\text { Total emissions of transportation in Puebla without } \\
\text { trucking }\end{array}$ & Tons $\mathrm{CO}_{2}$ & 1385078 & 1557877 \\
\hline $\begin{array}{l}\text { Reduction of emissions without trucking due to the } \\
\text { cyclist practice during the week }\end{array}$ & $\%$ & $0.7 \%$ & $1.0 \%$ \\
\hline $\begin{array}{l}\text { Reduction of emissions without trucking due to the } \\
\text { cyclist practice during the weekends and holidays }\end{array}$ & $\%$ & $1.3 \%$ & $2.4 \%$ \\
\hline $\begin{array}{l}\text { Reduction of emissions of } \mathrm{CO}_{2} \text { of urban transport } \\
\text { without trucking }\end{array}$ & $\%$ & $2.0 \%$ & $3.4 \%$ \\
\hline Reduction of emissions of $\mathrm{CO}_{2}$ of urban transport & $\%$ & $1.6 \%$ & $2.7 \%$ \\
\hline
\end{tabular}

The impact of scenario 1a, trucking excluded, gives an additional reduction of $\mathrm{CO}_{2}$ emissions of $1.14 \%$. If we add the various cumulative effects, the total impact becomes important. Thus, for example, the cumulative impact of a modal split which would $1.5 \%$ to $4.0 \%$ and a modal transfer of $0.6 \%$ in favor of Public Transport from the autos would give a total impact of $4.9 \%$ of emissions of $\mathrm{CO}_{2}$ caused by urban transportation of persons (3.8\% with trucking) and of $1.0 \%$ of total emissions. The scenario $2 \mathrm{a}$, with a modal split of $8.0 \%$ in 2020 and a transfer of $1.2 \%$ towards Public Transport would give an impact of $9.0 \%$ of urban transportation of persons $(8.2 \%$ with trucking) and of $1.8 \%$ of total emissions (Table 2). 
Table 2: Potential reduction of $\mathrm{CO}_{2}$ emissions in the city of Puebla scenario 1a of $4 \%$ and scenario $2 \mathrm{a}$ of $8 \%$ in 2020 applied to urban transportation of persons $(\%)$.

\begin{tabular}{|l|c|c|c|}
\hline \multicolumn{1}{|c|}{ Year } & $\mathbf{2 0 0 5}$ & $\mathbf{2 0 2 0}$ & $\mathbf{2 0 2 0}$ \\
\hline Modal split bicycle (observed 2005 and 2 senarios in 2020) & 1.5 & 4.0 & 8.0 \\
\hline $\begin{array}{l}\text { Direct reduction of } \mathrm{CO}_{2} \text { from Urban Transportation of } \\
\text { persons }\end{array}$ & 2.0 & $3.4^{*}$ & 6.7 \\
\hline $\begin{array}{l}\text { Indirect reduction of } \mathrm{CO}_{2} \text { by augmenting the use of Public } \\
\text { Transport (multimodality Bike-PT) }\end{array}$ & $\mathrm{x}$ & 1.45 & 2.9 \\
\hline Total reduction of $\mathrm{CO}_{2}$ of Urban Transportation of persons & 2.0 & 4.9 & 9.0 \\
\hline Total reduction of emissions of $\mathrm{CO}_{2}$ & 0.4 & 1.0 & 1.8 \\
\hline \multicolumn{2}{|l|}{ * Corresponds to 53 000 tons of $\mathrm{CO}_{2}$} \\
\hline
\end{tabular}

Although these results may vary in function of the rate of occupation of autos and of Public transportation, they show that the potential benefits of the use of the bicycle in the city are important.

\section{Conclusion}

Various best practices show undeniably that the bicycle is a viable option in midsized cities and also in metropolises as in Paris. The transportation policies of the sixties centered only on motorized modes are now outdated and the city planners are searching solutions to have more friendly cities for the non-motorized trips. In Mexico, based on the example of Puebla, which could be to a large extent, representative of a mid-sized city in Latin America, we can conclude that the population is largely open to the implementation of policies favorable to the use of the bicycle in the denser parts of the city, the historical centers, but also, as seen in the example of Monterrey in corridors of massive transportation where the bicycle could be used as a mode of multimodality with public transportation if appropriate measures were taken, such as safe parking stations for bicycles at the principal stations of Public Transportation. Even though various cities of Mexico are sensibilized to the practice of the bicycle in the city, we will need maturing the idea and that pro-bicycle measures be an integral part of urban transportation planning. In the paradigm which we presented an estimation of magnitude of the reduction of emissions of $\mathrm{CO}_{2}$ due to urban transportation, induced by the practice of the bicycle gives us a reduction of $3 \%$ of urban transportation of persons and of $0.7 \%$ of global emissions in medium scenarios of the practice of the bicycle for utilitarian an leisure purposes.

If we add the indirect impacts due to a modal shift favorable to Public Transportation in a context of measures favorable to intermodality BicyclePublic Transport, the impact could reach close to $5 \%$ of urban emissions and $1 \%$ of global emissions in medium scenarios and, respectively $9.0 \%$ and $1.8 \%$ in more extreme proactive scenarios. In terms of impact on global warming, the effect is thus perceptible and policies favorable to the use of the bicycle in the 
city appear to be one of the many measures possible which will be necessary to attain the objective of a reduction of global emissions of GHG.

Furthermore, these policies, according to various experiences have other positive effects such as a better quality of life in the city. In the case of Puebla the positive impact on Tourism could induce enormous economic benefits. In the Latin American context, such policies, at least in cities with a touristic vocation, should be financially and socialy viable.

\section{Acknowledgements}

This study received the support of: - the Academic Group in Urban and Regional Economics of the Faculty of Economics of the BUAP (Puebla) - the Vicerectoria de investigación y estudios de posgrado of the BUAP - the Colegio of Tlaxcala CONACYT (Mexico) - ECOS-NORD (CONACYT-ANUIES) program - the consulting firm in transportation LOGIT of Puebla.

\section{References}

[1] BIXI: http://www.bixi.com/accueil

[2] Blodgett, J., Parker, L. Greenhouse Gas Emissions: Perspectives on the Top 20 Emitters and Developed Versus Developing countries. Congressional Research Service, 2008.

[3] Bogotá? Como vamos? (2002), from telephone surveys; STT (2003), from 7600 face to face surveys).

[4] Bussière, Y., Collomb, J-L, Ravalet, E. "Cycling in the City and Reduction of Greenhouse Gas Emissions: The Case of Mexico", Marseilles, World Bank Fifth Urban Research Symposium 2009, 14p., 2009.

[5] Bussière, Y., Espinosa Torres, I., Collomb, L.-L. "Transporte sustentable: Modos no-motorizados en Lyon y Paris y su aplicabilidad en la Ciudad de Puebla", 6e Congreso Internacional de Urbanismo y Medio Ambiente, BUAP, Puebla, 21-23 Mayo, 2008, ppt., 2008.

[6] Bussière Y. "Demanda de transporte en Puebla: Comparación con Montreal y perspectivas". ch. 5 in Yves Bussière (éd.), Transporte Urbano en Latinoamérica y el Caribe: Estudios de casos (San José, Puebla, Puerto España, Puerto Príncipe), San Jose Costa Rica, Puebla, Montreal, FLACSO, BUAP, GIM, 109-132. 2005.

[7] Bussière, Y., Bernard, A. L'impact du vélo sur les gaz à effet de serre au Québec. Rapport de recherche pour Vélo-Québec. Montréal. INRSUrbanisation. 19 p., 2000. http://www.velo.qc.ca/velo_quebec/memoires /VeloetGESWord98.pdf

[8] C.E.R.T.U. L'enquête-ménages déplacements "méthode standard. Note méthodologique et annexes. Editions du CERTU, 295 p., 1998.

[9] Eastern Research Group. MOBILE5-Mexico Documentation and User's Guide. Prepared for the Western Governors' Association and Binational Advisory Committee by Eastern Research Group, Inc., Sacramento, CA, and Radian International, Sacramento, CA., 2000. 
[10] Groupe interuniversitaire de Montréal (G.I.M.). Enquête ménagestransport. Puebla, Pue. (Mexique), 1993-94. Rapport final. (sous la dir. de Rice, R.G., Bussière, Y., Chapleau, R.). Realised for the Government of the State of Puebla, Mexico, Estudio Integral de Vialidad y Transporte. Montreal, INRS-urbanisation, 1994.

[11] Instituto Nacional de Ecología de México- Secretaria de Medio Ambiente y Recursos Naturales (2002) National Greenhouse Gas Inventory 1990-2002, Report of México.

[12] LOGIT (Puebla, Mexique). Surveys realized on Transit users and Car drivers. Monterrey, Mexico, 2008.

[13] Papon, F. "Mûrissement social et pratique de la bicyclette", chap. 12 in Bussière, Y., Madre, J.-L., Démographie et Transport: Villes du Nord et Villes du Sud, Paris, l'Harmattan, 263-288, 2002.

[14] Ravalet, E., Bussière, Y., Collomb, J.-L. "Potentiel du vélo en ville: Une comparaison France-Mexique (Lyon et Puebla)", communication, XLVe Colloque ADSRLF 2008, 25-27 août, Rimouski, Québec, Canada, 2008.

[15] Richard, A. "La montée du vélo en libre-service: un nouveau mode de transport urbain à part entière", Conference, Montreal, Institut d'Urbanisme, Univ. of Montreal, 11 déc. ppt., 2009.

[16] Secretaria de los Transportes y de las Comunicaciones del Estado de Puebla Programa de Gestión de la Calidad del Aire en la Zona Metropolitana del Valle de Puebla 2006-2011, 2006.

[17] Suero, D.F. "La bicicleta como medio de transporte en la ciudad de Bogotá". Pdf. (around 2005). (htttp://colombus.uniandes.edu.co: 5050/dspace/bitstream1992/849/Paper_Investig_Diego_Suero.pdf).

[18] SYTRAL, Enquêtes ménage OD 1995 et 2006 de Lyon.

[19] Transflash. Vélo’v: un premier bilan?. CERTU. No 311, 2006.

[20] Ville \& Transports. Les vélos en libre service, No 433., 2007.

[21] Stern, Nicolas. Stern Review on the Economics of Climate Change, U.K., 700p. , 2006.

[22] Yanes Díaz, G. et al. Unidades Multifunctionales de Servicio Urbano del Centro Histórico de la Ciudad de Puebla, CONACYT, Puebla, 2008. 